dollars gathering information for the investigation and making site visits. Aside from the economic impact, five individuals were placed inappropriately on INH preventive therapy. Fortunately, no adverse reactions occurred due to the therapy.

Routine skin testing is an important TB surveillance tool in healthcare settings and may be useful among other high-risk populations. Appropriate techniques and materials must be used to ensure meaningful results are obtained. It has been said that "the $250 \mathrm{TU}$ product is sometimes useful in assessing the immunologic status of patients but has limited usefulness in the diagnosis of tuberculosis infection."12 In a study among patients known to be free of active $\mathrm{TB}, 12 \%$ reacted to the $5 \mathrm{TU}$, whereas $44 \%$ reacted to $250 \mathrm{TU}$, likely due to cross-reactivity to nontubercular mycobacteria. This increase in positive reactors with $250 \mathrm{TU}$ severely compromises the specificity for detection of $M$ tuberculosis. 15

The PPD Mantoux is an imperfect test, but it is the best currently available. Given the limitations on the test, it is imperative that it be used correctly. Careful planting, meticulous reading, attention to the epidemiology of TB, monitoring of product quality, and complete documentation in charts are critical components of an effective TB screening and control program.

\section{REFERENCES}

1. Centers for Disease Control and Prevention. Reported tuberculosis in the United States, 1995. August 1996:5.
2. Centers for Disease Control and Prevention. Essential components of a tuberculosis prevention and control program; and screening for tuberculosis and tuberculosis infection in high risk population: recommendations from the Advisory Council for the Elimination of Tuberculosis. MMWR 1995;44(RR-11):1.

3. Grabau JC, DiFerdinando GT, Novick LF. False-positive tuberculosis skin test results. Public Health Rep 1995;110:703-706.

4. Chaparas S, Vandiviere HM, Melvin I, Koch G, Becker C. Tuberculin test, variability with the Mantoux procedure. $\mathrm{Am}$ Rev Respir Dis 1985;132:175-177.

5. Huebner RE, Schein MF, Bass JB. The tuberculin skin test. Clin Infect Dis 1993;17:968-975.

6. Lifson AR, Watters JK, Thompson S, Crane CM, Wise F. Discrepancies in tuberculin skin testing results with two commercial products in a population of intravenous drug users. $J$ Infect Dis 1993;168:1048-1051.

7. Lanphear BP, Linnemann CC, Cannon CG. A high false-positive rate of tuberculosis associated with Aplisol: an investigation among health care workers. J Infect Dis 1994;169:703-704.

8. Mellor J. False-positive results of Mantoux tests. Can Med Assoc J 1985;132:1403.

9. Shands JW, Boeff D, Fauerbach L, Gutekunst RR. Tuberculin testing in a tertiary hospital: product variability. Infect Control Hosp Epidemiol 1994;15:758-760.

10. Cieslak JJ, Irwin RG, Dougherty PA, Miller GM. A pseudoepidemic of tuberculin skin test conversion caused by a particular lot of purified protein derivative of tuberculin test solution. Pediatr Infect Dis J 1995;14:392-393.

11. Gurevich I, Landry SM, Hunt EH, et. al. False-positive PPD reactions. Infect Control 1985;6:241-242.

12. American Thoracic Society. The tuberculin skin test. Am Rev Respir Dis 1981;124:356-363.

13. Blackshear J, Bravo E, Gesink D, Davies SF, Iber C, Johnson JR. False-positive tests with Parke-Davis Aplisol. Am Rev Respir Dis 1983;127:254.

14. Comstock GW. False tuberculin test results. Chest 1975; 68(suppl):465-469.

15. Nash DR, Douglas JE. Anergy in active pulmonary tuberculosis. A comparison between positive and negative reactors and an evaluation of $5 \mathrm{TU}$ and $250 \mathrm{TU}$ skin-test doses. Chest 1980;77:32-37.

\title{
TB Skin Testing of BCG-Vaccinated Children
}

\section{Gina Pugliese, RN, MS Martin S. Favero, $\mathrm{PhD}$}

Childhood tuberculosis (TB) causes an estimated 400,000 deaths annually worldwide and often is difficult to diagnose. Tuberculin skin tests (TSTs) often are part of the diagnostic algorithms for pediatric TB in developing countries, although their interpretation may be complicated by prior bacille Calmette-Guérin (BCG) vaccination. A recent study examined the prevalence and risk factors for TST reactivity in a population-based sample of children aged 3 to 60 months in Botswana, where BCG coverage exceeds $90 \%$ and $\mathrm{TB}$ rates approach 400 per 100,000 .

Of the 820 children tested, $92.3 \%$ had received BCG at birth. TST induration ranged from 0 to $21 \mathrm{~mm}$; $78 \%$ had $0 \mathrm{~mm}$, and $7 \%$ of children had $>10 \mathrm{~mm}$ induration. A positive TST $(>10 \mathrm{~mm})$ was not associated with age, clinical signs or symptoms, nutritional status, household size, tuberculin batch, or previous immunization with BCG, measles, or oral poliovirus vaccines. However, contact with any persons with reported TB was associated with a positive TST, as was having a mother with TB. The researchers concluded that prevalence of TST positivity was low in this highly BCGvaccinated population. The association between TST positivity and exposures to TB suggests that a positive TST indicates tuberculous infection and that TST remains a useful adjunct in the diagnosis of TB in this setting.

FROM: Lockman S, Tappero J, Kenyon T, et al. Tuberculin reactivity in a pediatric population with high BCG coverage. Presented at the 46th Annual Epidemic Intelligence Service Conference; April 14-18, 1997; Atlanta, GA. 